\title{
APORTE DE MATERIAL EM SUSPENSÃO NO BAIXO RIO SÃO FRANCISCO (SE/AL), EM DIFERENTES CONDIÇÕES HIDROLÓGICAS
}

\author{
MEDEIROS, P. R. P. ${ }^{1}$; KNOPPERS, B. ${ }^{2}$; SOUZA, W. F. L. ${ }^{3 *} \&$ OLIVEIRA, E. N. ${ }^{4}$ \\ 1 - Instituto de Geografia, Desenvolvimento e Meio Ambiente/ Laboratórios Integrados de Ciências \\ do Mar e Naturais, IGDEMA/LABMAR, Universidade Federal de Alagoas, UFAL, Maceió (AL). \\ 2 - Departamento de Geoquímica, Universidade Federal Fluminense, UFF, Niterói (RJ). \\ 3 - Divisão de Química Analítica, Instituto Nacional de Tecnologia, INT, Rio de Janeiro (RJ) \\ 4 - Departamento de Engenharia Oceânica, Instituto de Estudos do Mar Almirante Paulo Moreira, \\ IEAPM, Arraial do Cabo (RJ) \\ * Corresponding author: weber.landim@int.gov.br
}

\begin{abstract}
Medeiros, P. R. P.; Knoppers, B.; Souza, W. F. L. \& Oliveira, E. N. 2011. Contribution of suspended matter in the lower São Francisco River (SE/AL), across different hydrologic conditions. Braz. J. Aquat. Sci. Technol. 15(1): 42-53. ISSN 1983-9057. The São Francisco River estuary has since the Seventies been subject to the impact of a dam cascade constructed along its middle-lower semi-arid river course. Suspended matter and water fluxes were reduced both in their magnitude and natural seasonal pulsation. However, today's regulated fluxes are still prone to sporadic short-term perturbations induced by extreme climatic events in the drainage basin. This study addresses suspended matter fluxes of three anomalous events, one corresponding to the drought of 2001 and the other to the floods of 2004 and 2007. The drought event extended over the whole basin leading to low suspended matter concentrations of $<5 \mathrm{mg} / \mathrm{L}$ and fluxes of $0,2 \times 10^{6} \mathrm{t} / \mathrm{y}$ due to low discharges and efficient material retention by the dam reservoirs. In contrast, the flood of 2004 was generated by high precipitation in the middle-lower semi-arid basin and yielded higher concentrations of suspended matter with a pulse of up to $490 \mathrm{mg} / \mathrm{L}$ and fluxes of $7,7 \times 10^{6} \mathrm{t} / \mathrm{y}$. The flood of 2007 produced lower suspended matter concentrations of up to $25 \mathrm{mg} / \mathrm{L}$ and fluxes of $1,1 \times 10^{6} \mathrm{t} / \mathrm{y}$, as it was induced by precipitation in the upper basin and materials were retained by the dams. The results exemplify that spatial differences of precipitation in the basin in relation to the location of the dam cascade generate different water run-off and material yields to the coast.
\end{abstract}

Keywords: Dams, Freshwater discharge, Suspended matter, Extreme Events.

\section{INTRODUÇÃO}

A concentração de material em suspensão de um rio é controlada por diversos fatores naturais da bacia hidrográfica, dentre os quais se destacam: a geologia, geomorfologia, pedologia, cobertura vegetal natural, uso do solo e fatores climáticos, dentre outros. No entanto, as pressões antrópicas têm progressivamente aumentado, alcançando um patamar em que os sistemas de drenagem não podem ser mais definidos somente pelas relações climáticas e morfológicas naturais (Souza \& Knoppers, 2003). Fatores antrópicos, como o uso do solo e a retirada da cobertura vegetal natural, dependendo da sua magnitude e intensidade, tendem a alterar a dinâmica natural de sedimentos em uma bacia e seu transporte para o ambiente fluvial. O fluxo de material em suspensão também é afetado pela construção de barragens em rios (Halim, 1991).

Segundo Milliman (1991), os rios contribuem com aproximadamente $70 \%$ do aporte total mundial de sedimentos para o oceano. Estimativas dos fluxos globais de sedimentos estão na ordem de $18 \times 10^{9}$ toneladas/ano. Este valor representa a contribuição dos grandes rios mais estudados, sendo negligenciados os aportes de aproximadamente 20.000 rios de médio e pequeno porte pela escassez de informações (Milliman \& Syvitsky, 1992; Vörösmarty et al., 1997; Hay, 1998). A contribuição dos rios de médio e pequeno porte é pouco documentado, devido à falta de estudos de monitoramento locais e regionais mais consistentes e principalmente, sobre a natureza dos impactos antrópicos que afetam a descarga específica de sedimentos, tal como o desmatamento, a erosão, a agricultura e a construção de barragens (Vörösmarty et al., 1997; Meybeck, 2001).

O rio São Francisco enquadra-se na tipologia de rio de médio a grande porte $\left(A_{B}\right.$ de $\left.640 \times 10^{3} \mathrm{Km}^{2}\right)$, apresenta relevância ecológica, econômica e social, sendo utilizado na geração de energia elétrica, irrigação, navegação, abastecimento de água, pesca e aqüicultura. Em comparação com a vazão, que é medida de maneira sistemática desde 1936, estudos relacionados ao material em suspensão são relativamente escassos, destacando-se os realizados por Milliman (1975); Bessa e Paredes (1990), Santos (1993); Medeiros (2003); Souza \& Knoppers (2003); Medeiros et al. (2007).

Este estudo quantifica o aporte fluvial de material em suspensão durante eventos climáticos extremos de seca em 2001 e de enchentes dos anos de 2004 e 


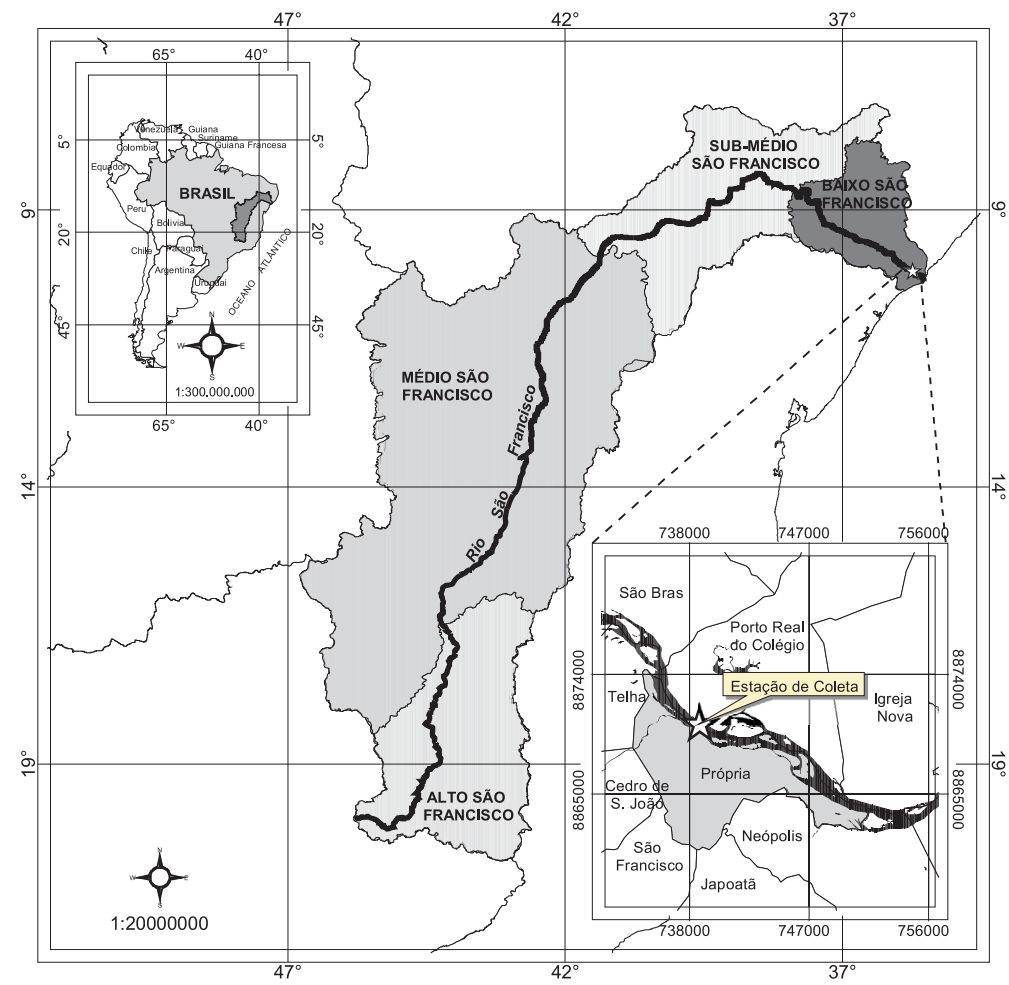

Figura 1 - Setores Fisiográficos da Região Hidrográfica do Rio São Francisco, com detalhe na área de estudo.

2007, que geraram diferentes fontes e magnitudes no suprimento de sedimentos em suspensão da bacia à zona costeira.

\section{ÁREA DE ESTUDO}

\section{Divisões fisiográficas e climas}

O rio São Francisco $\left(L=2.863 \mathrm{~km}, A_{B}=640 \times 10^{3}\right.$ $\mathrm{km}^{2}$ ) percorre diferentes setores fisiográficos: Alto, Médio, Sub-médio e Baixo Rio São Francisco (Figura 1); antes de desembocar no Oceano Atlântico Sul na divisa dos Estados de Sergipe e Alagoas, NE-Brasil. Os setores são caracterizados especialmente pelos diferentes domínios climáticos: com clima tropical úmido do tipo Köppen Aw no Alto; do tipo Aw à BShw no Médio; tipo semi-árido BShw no Sub-Médio, e do tipo AS, quente e úmido, no Baixo (Bernardes, 1951). A precipitação total anual no Baixo São Francisco varia de $1.250 \mathrm{~mm} 1.500 \mathrm{~mm}$, a estação chuvosa em seu Baixo curso é nos meses de maio-junho-julho, sendo a temperatura média anual de $24^{\circ} \mathrm{C}$ (Nimer, 1972).

\section{Geologia e Geomorfologia do Baixo Rio São Francisco}

A geologia sedimentar é composta por formações do Cretáceo (cordões montanhosos), do Terciário (Formação Barreiras) e do Quaternário (aluviões e dunas). Ponte (1969) reconheceu três províncias geomorfológicas com características semelhantes às regiões ocupadas pela planície costeira do rio São Francisco. A zona de relevo ondulado está relacionada às rochas pré-Cambrianas dos grupos Baixo São Francisco e Sergipe, onde as diferenças litológicas são responsáveis pelas variações na morfologia do terreno. Tabuleiros Terciários da Formação Barreiras originam uma superfície plana e pouco dissecada que integra a maior parte dos sedimentos do Sub-Médio e Baixo Rio São Francisco. A Planície Quaternária é formada por depósitos de origem marinha, lacustre e eólica, que se concentram na região do delta estuarino.

\section{Alterações hidrológicas da bacia do Rio São Francisco}

Dentre os principais impactos antrópicos à bacia do Rio São Francisco, o aproveitamento hidroelétrico se destaca. As Usinas Hidroelétricas (UHE's) são especialmente relevantes no seu médio-baixo curso, onde a ausência de grandes povoamentos e de afluentes significativos, fazem com que a retenção de materiais e a regulação das vazões pelas barragens das UHE's sejam o parâmetro predominante das características fluviais, da formação da pluma costeira e do aporte de materiais ao oceano (Souza \& Knoppers, 2003; Knoppers et al., 2005; Medeiros et al.; 2007). As alterações hidrológicas promovidas pelas UHE's remontam a década de 1950 (Tabela 1), e foram sendo progressivamente agravadas pela sucessão de barragens em 
Braz. J. Aquat. Sci. Technol., 2011, 15(1): 42-53.

Tabela 1 - Principais usinas hidroelétricas (UHE), localização e volume de armazenamento das barragens no rio São Francisco. (Fonte CHESF, 2008).

\begin{tabular}{|c|c|c|c|c|}
\hline UHE & Operação & Setor & Volume $\left(\mathrm{km}^{3}\right)$ & Potência (kw) \\
\hline Três Marias & 1952 & Alto & 21 & 387.600 \\
\hline P.Afonso I a IV & 1955 a 1980 & Sub-Médio & 0,1 & 180.000 \\
\hline Sobradinho & 1980 & Sub-médio & 34 & 1.050 .000 \\
\hline Itaparica & 1988 & Sub-médio & 10,8 & 1.500 .000 \\
\hline Moxotó & 1978 & Sub-médio & 1,2 & 440.000 \\
\hline Xingó & 1994 & Baixo & 3,8 & 3.000 .000 \\
\hline
\end{tabular}

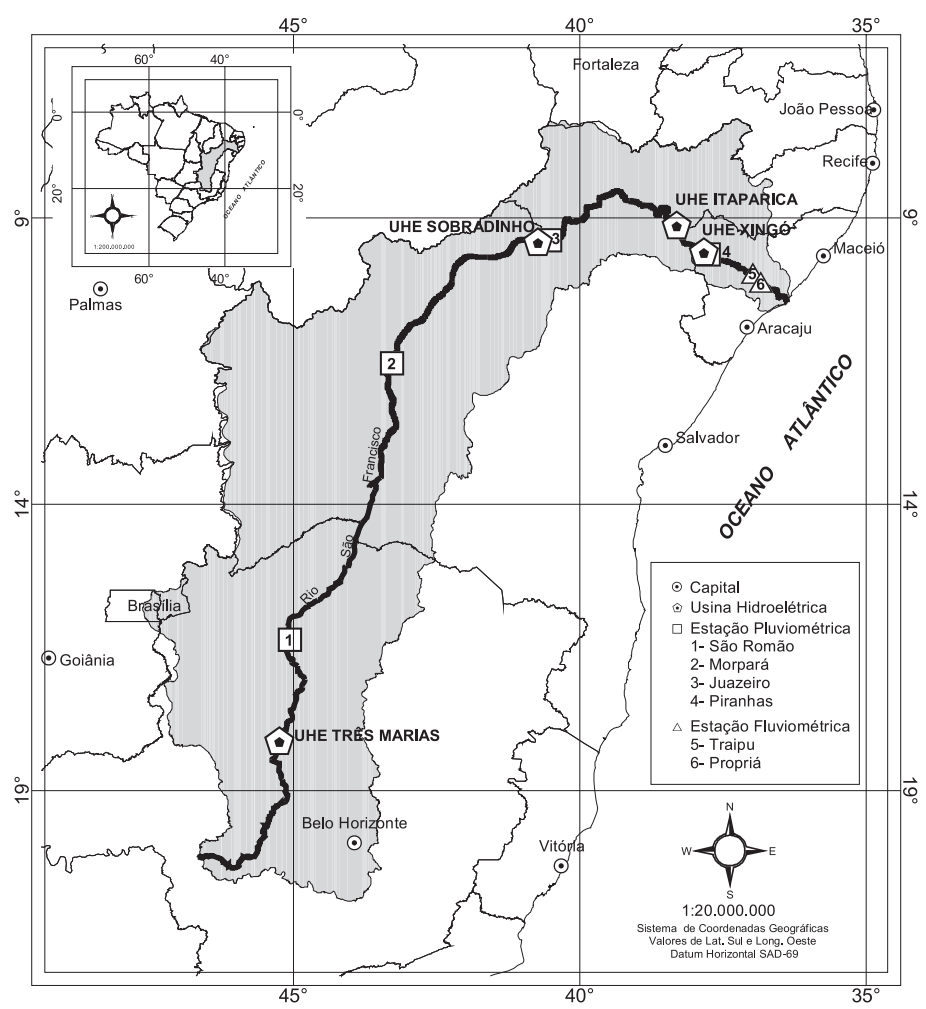

Figura 2 - Bacia Hidrográfica do Rio São Francisco; principais usinas hidroelétricas (UHE); estações pluviométricas de São Romão (Alto), Morpará (Médio), Juazeiro (Sub-Médio) e Piranhas (Baixo); estações fluviométricas de Traipu (AL) e Propria (SE). Fonte:Adaptado de ANA (2008).

cascata ao longo do curso principal do setor sub-médio do rio São Francisco (Figura 2) .

Em razão do sistema de barragens em cascata, o rio São Francisco sofre vários impactos comuns a outros rios barrados como a retenção de sedimentos e redução da magnitude e da pulsação natural da vazão (Halim, 1991; Souza \& Knoppers, 2003). De acordo com Knoppers et al. (2005) e Medeiros et al. (2007) estes impactos tiveram seu ápice com a instalação em 1994 da UHE Xingó localizada a $180 \mathrm{Km}$ da costa, que devido a operação em conjunto com as demais UHE's promoveu uma supressão significativa da variação sazonal das descargas de água (Figura 3), medida $80 \mathrm{~km}$ da costa na estação fluviométrica de Propriá (SE).

\section{MATERIAIS E MÉTODOS}

Neste estudo, foram realizadas amostragens nos anos de 2001, 2004 e 2007, com periodicidade mensal para a determinação das concentrações e aportes de sedimentos em suspensão em uma estação fixa próximo a ponte rodo-ferroviária entre as cidades de Propriá (SE) e Porto Real do Colégio (AL) (Lat. 10¹2'S e Long. $36^{\circ} 49^{\prime} \mathrm{W}$ ). A estação é localizada $80 \mathrm{~km}$ a montante da foz do rio São Francisco e a $100 \mathrm{~km}$ jusante da UHE Xingó (CHESF) e representa a estação fluviométrica de Propriá, 49705000 da ANA (Fig. 2).

Dados da precipitação em estações pluviométricas localizadas nos setores Alto (São Romão, 


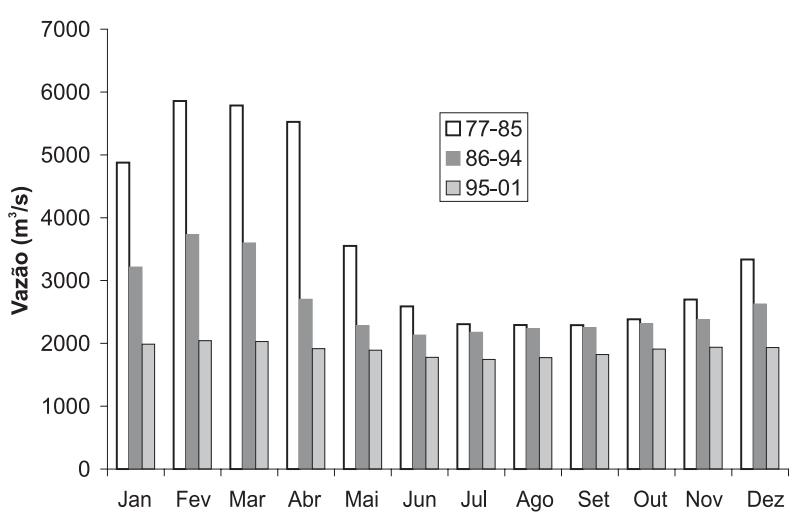

Figura 3 - Variação das médias mensais da vazão da estação de Própria (SE), referentes aos estágios identificados. Fonte: Adaptado de Medeiros et al. (2007).

cód.: 01645000), Médio (Morpará, cód.: 01143002), SubMédio (Juazeiro, cód.: 00940024) e Baixo (Piranhas, cód.: 00937023) da bacia do Rio São Francisco (Fig. 2) foram obtidos junto ao banco de dados da ANA (2008 e 2009) (http://www.ana.gov.br) para avaliar a influência da distribuição da precipitação sobre a produção de sedimentos na bacia, o seu suprimento ao estuário e a formação da pluma costeira.

As coletas de amostras de água para análise de material em suspensão foram realizadas em 4 setores. Estes setores foram escolhidos baseados no estudo de Medeiros et al. (2007) sobre as vazões em um perfil transversal realizado na mesma estação. As amostras foram coletadas com garrafa de coleta tipo Van Dorn de acrílico, em sub-superfície (em torno de 20 centímetros abaixo da linha de água). Após a coleta, as amostras foram armazenadas em frascos plásticos com volume de 5 litros, acondicionadas em caixa isopor e transportadas refrigeradas sob gelo. As amostras foram filtradas (Whatman GF/F, $\varnothing=47 \mathrm{~mm}$ ) e o peso do material em suspensão foi determinado segundo a metodologia descrita por Strickland \& Parsons (1972).

O fluxo de material em suspensão foi determinado usando-se vazões fornecidas pela CHESF e os coeficientes de vazão estimados nas calibrações de

$$
F_{m}=\mathrm{Q} \sum_{i=\mathrm{I}}^{\mathrm{N}} a_{i} C_{i}
$$

Medeiros et al. (2007), e conforme o descrito pela expressão abaixo: suspensão $i$;

Onde: $F_{m}=$ fluxo momentâneo da matéria em

$Q=\operatorname{vazão}\left(\mathrm{m}^{3} / \mathrm{s}\right)$;

$a_{i}=$ coeficiente da vazão nos setores $i$ de I até

$\mathrm{N}$, neste caso $\mathrm{N}=\mathrm{IV}$;

$C_{i}=$ concentração da matéria em suspensão.
Uma vez determinado o fluxo momentâneo $\left(\mathrm{F}_{\mathrm{m}}\right)$ do material $m$, estimaram-se as cargas diárias do material, segundo $Q m=0,0864 \mathrm{Fm}$, onde $Q m$ é a carga diária expressa em toneladas. A carga total mensal foi obtida pela multiplicação da carga diária $Q m$ pelo número de dias do mês em questão.

\section{RESULTADOS E DISCUSSÃO}

A discussão sobre o impacto de barragens ao meio ambiente é de preocupação internacional (Vorosmarty et al., 1997; Hay, 1998; Syvitski et al., 2005) e nacional (Tundisi et al., 1998; Knoppers et al., 2006; Medeiros et al., 2007). As barragens promovem alterações físicas, químicas e biológicas na água e nos sedimentos armazenados nos seus reservatórios, influenciando processos hidrológicos e biogeoquímicos nos rios, estuários e ecossistemas costeiros.

Diversos estudos demonstram que as atividades humanas e as mudanças globais são os fatores mais importantes que atuam sobre os fluxos de sedimentos e a construção de barragens é considerada a principal causa no declínio dos fluxos de sedimentos para o oceano (Syvitski et al., 2003; Vorosmarty et al., 2003; Syvitski et al., 2005; Walling, 2006)

\section{Condições de contorno: Precipitação e vazão}

Os três ciclos anuais estudados se referem a condições distintas no regime de precipitação (Fig. 4) e como conseqüência de vazão (Fig. 5). O ano de 2001 se caracterizou por precipitações bem abaixo das normais climatológicas, com níveis críticos dos reservatórios das hidroelétricas num período conhecido como a crise de energia elétrica. Por sua vez os ciclos anuais de 2004 e 2007 foram caracterizados por precipitações elevadas que levaram a abertura das comportas do vertedouro da UHE Xingó pela primeira vez desde a sua entrada em operação em 1994. Este comportamento sugere de antemão a possibilidade de vazões mais acentuadas e com maior capacidade de transporte de materiais pela diminuição do tempo de residência das águas dos reservatórios e do rio ao longo de todo o sistema de barragens, em especial nos meses de Janeiro e Fevereiro.

A avaliação das precipitações em estações pluviométricas ao longo da calha principal nos setores do Alto, Médio, Sub-Médio e Baixo Rio São Francisco (Fig. 4) demonstra que para o ano hidrológico de 2001 as precipitações foram muito inferiores a observada para a média histórica de todos os setores. A recuperação das precipitações ocorreu a partir de setembro na estação do Alto Rio São Francisco. No ano de 2004 constatou-se uma situação contrária a de 2001 , onde as precipitações são significativamente maiores em com- 

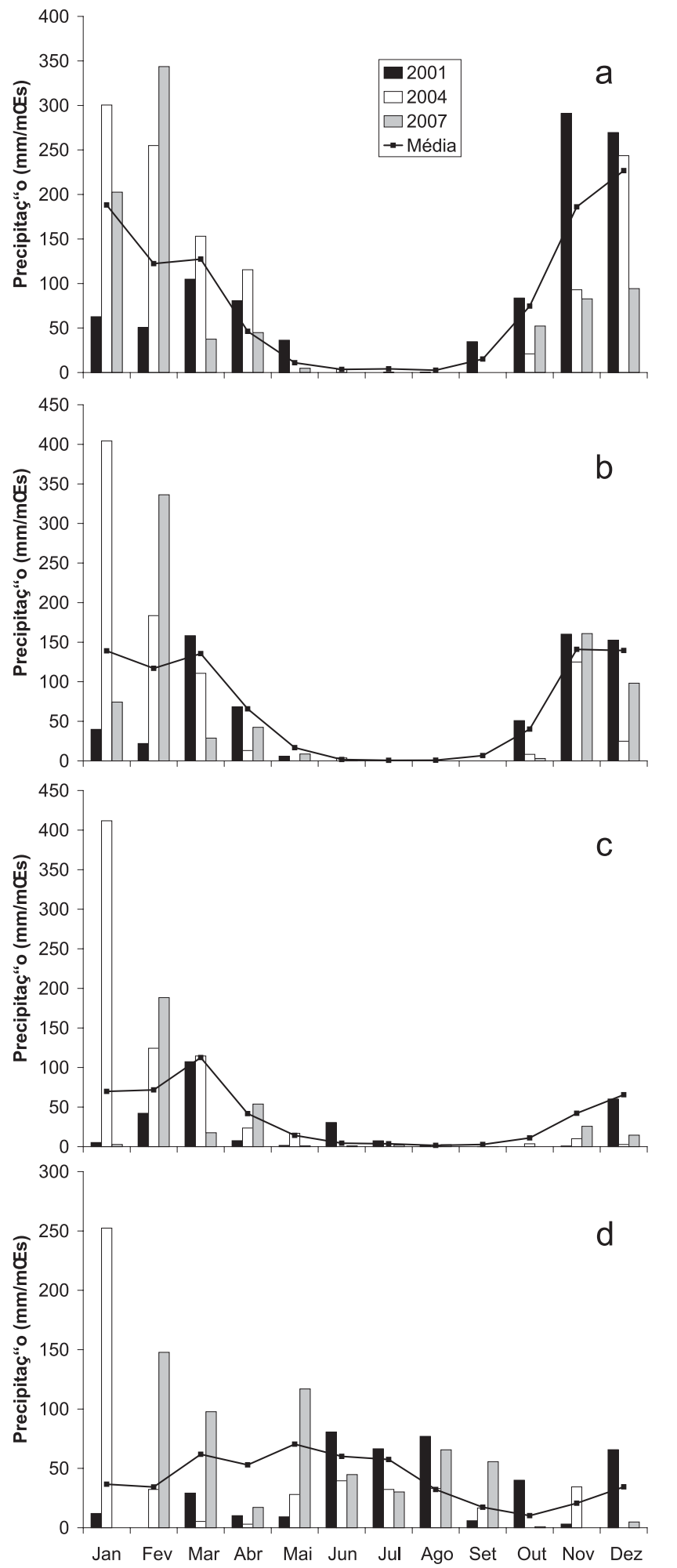

Figura 4 - Distribuição mensal da precipitação no período de estudo e a média histórica nas estações do Alto (a), Médio (b), SubMédio(c) e Baixo(d) Rio São Francisco. Fonte: ANA (2008 e 2009).

paração a média histórica, em todos os setores do Alto ao Baixo Rio São Francisco (Fig. 4). Em de 2007, comportamento similar é observado, com maior preci-

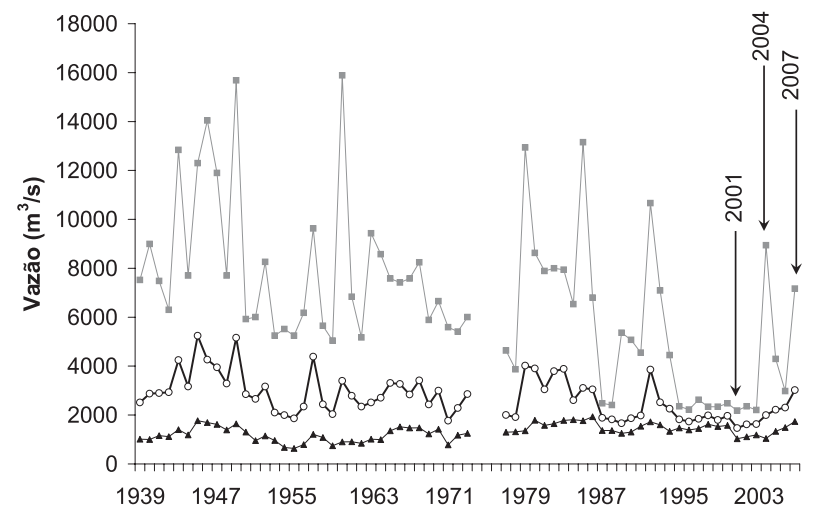

Figura 5 - Distribuição das vazões médias, mínimas e máximas anuais na estação de Traipu (cód.:49660000) a $120 \mathrm{Km}$ da foz. Fonte: ANA (2009).

pitação nas estações do Alto e Médio Rio São Francisco e mais concentradas no mês de Fevereiro.

Na Figura 5 observa-se para a vazão na estação de Traipú (AL; 120 km da costa), que desde 1939 os eventos extremos de mínimos e máximos de vazão tem sua magnitude média diminuída e mesmo o evento de drásticas conseqüências econômicas da crise de energia elétrica de $2001\left(Q_{\text {méd. }}=1468 \mathrm{~m}^{3} / \mathrm{s} Q_{\text {min }}=1032 \mathrm{~m}^{3} /\right.$ s) não se diferenciou muito das médias anuais e vazões mínimas de $1955\left(Q_{\text {méd. }}=1862 \mathrm{~m}^{3} / \mathrm{s} ; Q_{\text {min }}=637\right.$ $\left.\mathrm{m}^{3} / \mathrm{s}\right)$ ou $1971\left(Q_{\text {méd. }}=1768 \mathrm{~m}^{3} / \mathrm{s} ; Q_{\text {min }}=781 \mathrm{~m}^{3} / \mathrm{s}\right)$. Estes resultados representam um clássico exemplo da diminuição de amplitudes de máximos e mínimos em sistemas impactados por barragens (Halim, 1991; Souza \& Knoppers, 2003). Desta forma os períodos avaliados neste estudo representam a oportunidade de avaliar o impacto das barragens sobre o comportamento das concentrações e fluxos de materiais em suspensão e suprimento de sedimentos para o baixo Rio São Francisco e seu estuário

Em condições médias, o regime diferenciado de contribuição dos quatro (4) setores fisiográficos da bacia (Alto, Médio, Sub-Médio e Baixo) para a vazão total é estimada em $42,2 \%, 51,4 \%, 5,7 \%$ e $0,7 \%$, respectivamente (http://www.ana.gov.br, 2008). Neste cenário, é razoável afirmar que sob os eventos climáticos extremos observados nos anos de estudo (Fig. 5), que a seca do ano de 2001 teve suas vazões reguladas pelo sistema de barragens em cascata. Já os eventos de cheias do ano de 2004 proporcionaram contribuições de toda a bacia para a vazão total, devido a elevada precipitação ao longo de todos os setores com maior ênfase ao Baixo São Francisco onde a ausência de barramentos pode ter provocado uma maior eficiência no escoamento superficial. Por sua vez, as maiores precipitações aliadas a já natural maior contribuição dos setores Alto e Médio para a vazão total tenham exercido uma maior contribuição ás cheias de 2007. 


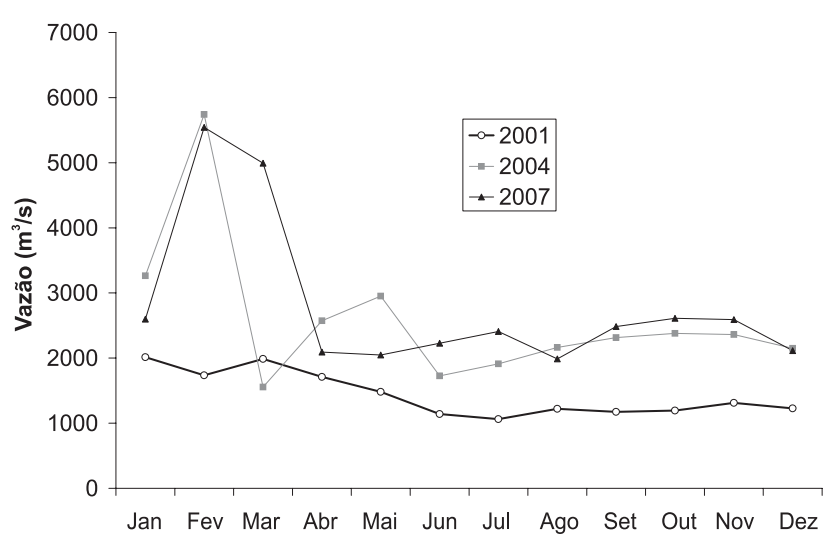

Figura 6 - Vazões médias mensais para os anos de 2001, 2004 e 2007 na UHE do Xingó. Fonte: CHESF (2008).

\section{O Impacto do Sistema de Barragens}

A Figura 6 representa o regime de vazões diferenciado para os anos hidrológicos de 2001 (baixa vazão ao longo do ano), e de cheias pronunciadas de fevereiro a março de 2007. As vazões médias mensais do rio São Francisco medidas na UHE do Xingó (Fig. 6), mostram que as vazões médias mensais do ano de 2001 (excetuando-se os meses de janeiro e março) foram inferiores às ocorridas nos ano de 2004 e 2007. Em termos de vazões médias anuais observa-se que o ano hidrológico de 2001 (média de $1496 \mathrm{~m}^{3} / \mathrm{s} \pm 373 \mathrm{~m}^{3} /$ s) foi inferior ao de 2004 (média de $1.970 \mathrm{~m}^{3} / \mathrm{s} \pm 516$ $\mathrm{m}^{3} / \mathrm{s}$ ) e este por sua vez foi também inferior ao ano de 2007 (média de $2.808 \mathrm{~m}^{3} / \mathrm{s} \pm 1.177 \mathrm{~m}^{3} / \mathrm{s}$ ).

Os dados de vazão para a foz do Rio São Francisco (Fig. 6), medidas na UHE do Xingó representam a otimização dos reservatórios em cascata para a acumulação de água e produção de energia elétrica conforme as necessidades do Sistema Elétrico Nacional. Isto é melhor observado na Figura 7, onde a comparação da vazão afluente aos reservatórios e sua vazão defluente demonstra que no ano de 2004, com elevadas precipitações em toda a bacia geraram elevados rendimentos de água doce (vazão).

No entanto as altas vazões de janeiro a março foram utilizadas pelos dois principais reservatórios do sistema (Três Marias, i.e março/2004 e V ${ }_{\text {afluente }} \mathrm{H}^{\prime \prime} 3.500$ $\mathrm{m}^{3} / \mathrm{s}$ e $V_{\text {defluente }} H^{\prime \prime} 500 \mathrm{~m}^{3} / \mathrm{s}$ ) e (Sobradinho, i.e março/ $2004 \mathrm{~V}_{\text {afluente }} \mathrm{H}^{\prime \prime} 5.500 \mathrm{~m}^{3} / \mathrm{s}$ e $\mathrm{V}_{\text {defluente }} \mathrm{H}^{\prime \prime} 1.000 \mathrm{~m}^{3} / \mathrm{s}$ ) para recompor o volume dos reservatórios aumentando significativamente o tempo de residência destes reservatórios e a retenção de sedimentos (Figura 7, quadro menor). Neste ano de 2004 as vazões geradas para a foz tiveram origem principalmente no trecho a jusante da barragem de Sobradinho (do setor Sub-Médio ao Baixo São Francisco) com retenção mínima no reservatório de Xingó onde toda a vazão afluente foi liberada na geração de energia e através dos vertedouros. A vazão gerada neste trecho do baixo São Francisco al-

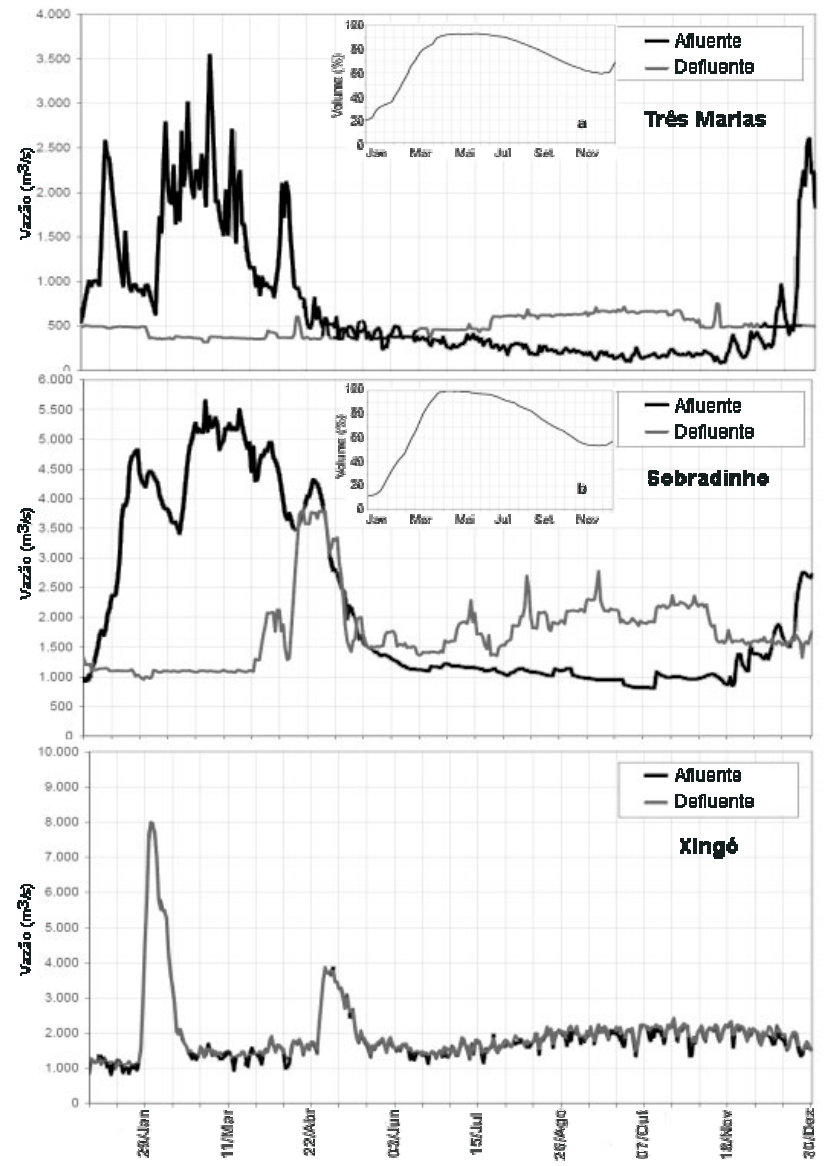

Figura 7 - Vazões afluentes e defluentes do ano de 2004 nos reservatórios de Três Marias, Sobradinho e Xingó. O volume armazenado pelos reservatórios de Três Marias e Sobradinho pode ser visualizado nos gráficos a e b. Adaptado de ANA (2005).

cançou um máximo de $7.000 \mathrm{~m}^{3} / \mathrm{s}$ no início de fevereiro (i.e fevereiro/2004 $\mathrm{V}_{\text {deffuente Sobradinho }} \mathrm{H}^{\prime \prime} 1.000 \mathrm{~m}^{3} / \mathrm{s} \mathrm{e}_{\text {afluente }}$ Xingó $\mathrm{H}^{\prime \prime} 8.000 \mathrm{~m}^{3} / \mathrm{s}$ ) com um adicional de aproximadamente $2.900 \mathrm{~m}^{3} / \mathrm{s}$ gerado pela bacia a jusante de Xingó até a estação de Propriá (cód. 49705000) que apresentou vazão no início de fevereiro de 2004 de aproximadamente $9.900 \mathrm{~m}^{3} / \mathrm{s}$; (http://www.ana.gov.br, 2008). Este comportamento tem significativa influência na capacidade de produção e transporte de sedimentos devido aos menores tempos de residência, e retenção de sedimentos nos reservatórios, e pela lavagem dos sedimentos acumulados na bacia do Baixo São Francisco.

A influência antrópica da operação do sistema de barragens em cascata também é observada nos demais anos e, em especial nos períodos críticos de seca e cheia na região do Rio São Francisco (Fig. 8). No ano de 2001, o suprimento das vazões, praticamente ao nível de vazões ecológicas mínimas entre 1.200 e 2.200 $\mathrm{m}^{3} / \mathrm{s}$ (Medeiros, 2003), foi primordialmente controlado pelos reservatórios em cascata e em especial pelos de Sobradinho e Luiz Gonzaga (Itaparica). Em 2004 as precipitações no Sub-Médio e baixo Rio São Francisco 
permitiram a retenção das vazões afluentes nos reservatórios de Três Marias, Sobradinho e Luiz Gonzaga (Itaparica), onde o volume de armazenamento deste último alcançou níveis máximos de 99,7 \% em 01/02/ 2004 (Fig. 8), sendo que as vazões na foz foram geradas principalmente no Baixo São Francisco. Em 2007 as chuvas concentradas nas regiões dos setores Altos e Médio permitiram o armazenamento de volumes acima de $80 \%$ nos reservatórios de Três Marias e Sobradinho. Do reservatório de Sobradinho até reservatório de Luiz Gonzaga (Itaparica) as vazões defluentes estavam ao redor de $6.000 \mathrm{~m}^{3} / \mathrm{s}$. Permanecendo assim até a defluência de Xingó, sugerindo origem das vazões no Alto e Médio São Francisco, e que estas foram atenuadas ao longo das barragens em cascata, promovendo uma maior retenção de materiais.

\section{Fluxos de material em Suspensão}

Em condições naturais, as concentrações e fluxos de material em suspensão em rios têm estreita relação com a vazão (Restrepo \& Kjerfve, 2000). O aumento da vazão intensifica a velocidade de escoamento fluvial, possibilitando maior capacidade de transporte e erosão das margens, incrementando dessa forma, o material particulado e dissolvido transportado. Por sua vez, Milliman \& Syvitsky (1992) mostraram claramente a relação dos rendimentos (produção normalizada pela área da bacia) de material em suspensão, com as diferentes características morfológicas das bacias de drenagem (cota da nascente, comprimento, inclinação média). No entanto as relações de parâmetros morfológicos e da vazão sobre a produção de material em suspensão é consideravelmente altera-
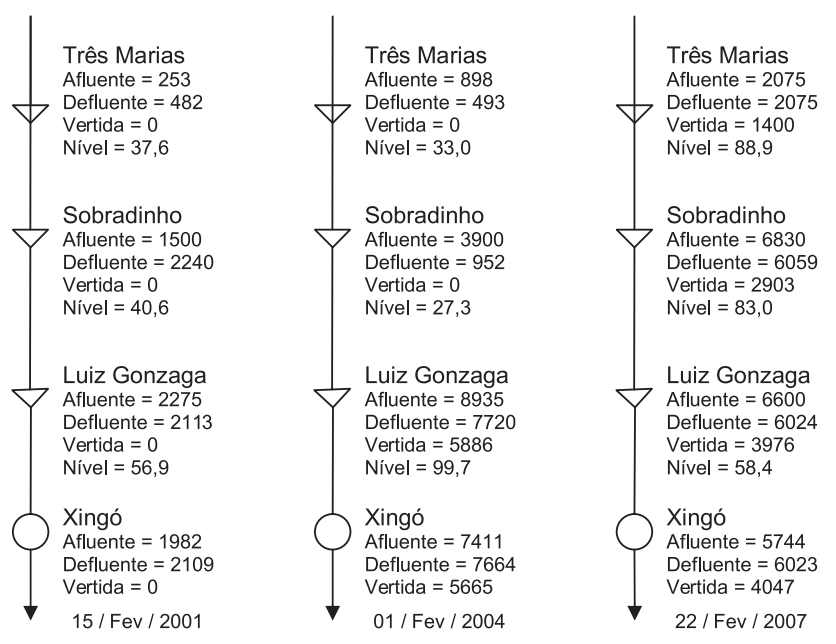

Figura 8 - Diagrama de operação das principais barragens (Três Marias, Sobradinho, Luiz Gonzaga e Xingó) do sistema em cascata do Rio São Francisco em exemplos representativos dos eventos de seca de 2001 (15/02/2001) e das enchentes de 2004 (01/ 02/2004) e 2007 (22/02/2007). Vazões efluentes, defluentes e vertidas em $\mathrm{m}^{3} / \mathrm{s}$ e nível dos reservatórios em \% do volume total. Fonte: ONS, 2001; 2004 e 2007.

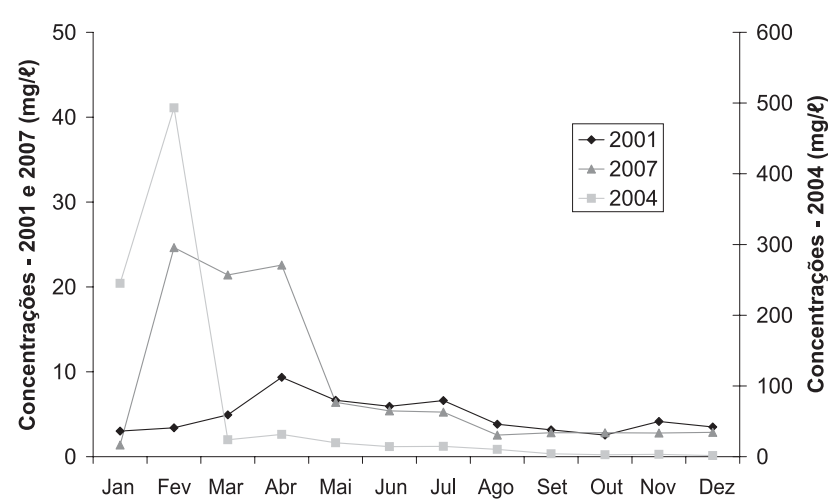

Figura 9 - Concentrações de material em suspensão nos anos de 2001 e 2007 e 2004 na estação fixa de Propriá.

da em função dos impactos antrópicos sobre as bacias de drenagem (Souza \& Knoppers, 2003).

\section{Concentrações de material em suspensão}

A análise das concentrações de material em suspensão na estação fixa em Propriá (Fig. 9), demonstra que no evento de seca (2001) as concentrações foram extremamente baixas com média de $4,8 \mathrm{mg} /-$ ! e variação entre 2,5 a 9,3 mg/-!. Níveis de base da concentração de material em suspensão são de difícil determinação devido à ausência de dados e as sucessivas alterações provocadas ao sistema. Entretanto dados no período de 2000 a $2003(n=15)$ para a estação fluviométrica de Propriaá (http://www.ana.gov.br,2008) apresentaram concentrações cerca de 3 vezes superiores às obtidas em 2001 (média $=13,3 \mathrm{mg} /-$ !) entre 5,3 a $35,7 \mathrm{mg} /-$ !). Estes resultados evidenciam os efeitos da baixa pluviosidade de 2001 e o intenso controle das vazões pelo sistema de barragens em cascata no período da crise de energia elétrica.

As concentrações do ano de 2004 revelam a origem das chuvas e vazões, bem como do menor tempo de residência nos reservatórios. As concentrações no evento das cheias de Jan/Fev de 2004, foram ao menos duas ordens de grandeza superiores (i.e. $493 \mathrm{mgMS} /$ -!) aos níveis de base encontrados em 2001. Em termos anuais os valores médios de material em suspensão foram de 72,0 mg/-!, mas variaram entre 1,6 a 493 $\mathrm{mg} /-$ ! em função de valores extremamente baixos de 1,6 a 3,2 mg/-! no período de Outubro a Dezembro de 2004. A ausência de precipitações significativas para a bacia no período posterior a Fevereiro e a acumulação de água nos reservatório para o período seco aumentou os tempos de residência dos reservatórios e a capacidade de transporte de sedimentos resultando nas baixas concentrações observadas ao final deste ano.

As cheias de 2007 foram mais prolongadas devido a elevada acumulação de água nos reservatórios do Alto e Sub-Médio Rio São Francisco que promoveram a manutenção de cheias para a foz de Janeiro a Abril de 2007. Embora, a origem das cheias nos setores 

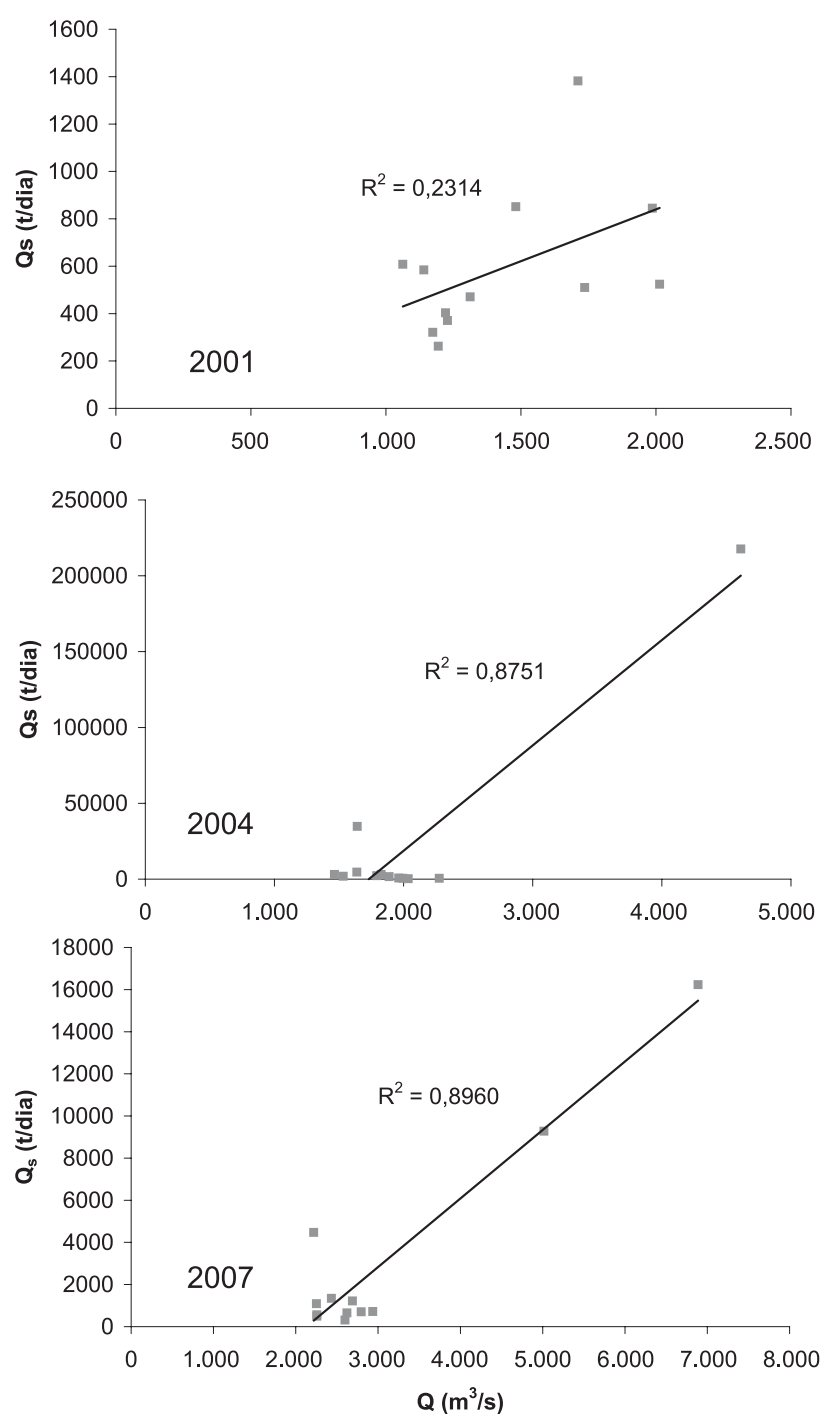

Figura 10 - Relações da descarga diária de sedimentos em suspensão, $\mathrm{Q}_{\mathrm{s}}$ (t/dia) e a vazão média diária, $\mathrm{Q}\left(\mathrm{m}^{3} / \mathrm{s}\right)$, para os anos de 2001, 2004 e 2007.

superiores da bacia tenha promovido uma diminuição nos tempos de residência, a atenuação pelo sistema de barragens em cascata e a ausência de produção significativa de sedimentos no baixo São Rio Francisco a jusante de Xingó resultou em concentrações de material em suspensão (média $=8,4 \mathrm{mg} /-$ !, faixa de 1,4 a 24,6 mg/-!) bem inferiores ao do ano 2004 e pouco diferentes a dos níveis de base relatados para o ano de 2001.

\section{Relações da Vazão com a Carga de material em Suspensão}

A relação da vazão com a carga de material em suspensão no Rio São Francisco foi pouco significativa para os anos de estudo (Fig. 10). Os maiores coeficientes de regressão obtidos para os anos de 2004 e 2007, evidenciam um comportamento da correlação espúria da curva, dominada pelo único ponto do pico

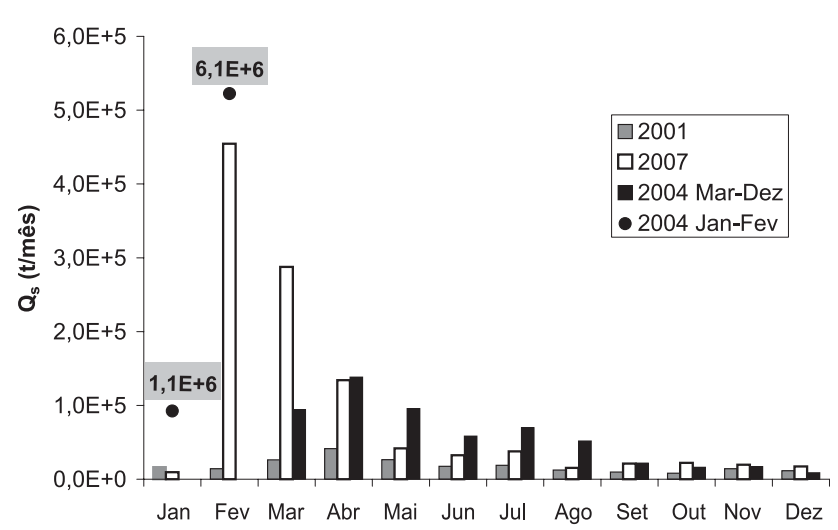

Figura 11 - Quantidade mensal ( $t /$ mês) de sedimentos em suspensão $\left(Q_{s}\right)$ nos anos de 2001, 2004 e 2007 na estação fixa de Propriá. Observe a ordem de grandeza (pontos) superior de Janeiro e Fevereiro de 2004.

de maior vazão e carga de material em suspensão dos eventos de fevereiro, enquanto os valores do restante do ano se mantém agrupados dentro de um patamar baixo com uma alta variabilidade. No ano de 2007 observa-se um padrão similar, onde os dois maiores eventos de transporte de material estão alinhados entre si e o centro de uma grande nuvem de dispersão dos resultados de vazão em torno de 2.000 a 3.000 m³.s.

A dificuldade de estabelecer correlações significativas entre a vazão e a concentração de matéria em suspensão sugere que as alterações hidrológicas oriundas do impacto das barragens sejam responsáveis pelo ocorrido. Muito embora a ausência de amostragens mais representativas e melhor distribuídas nas faixas de vazão encontradas possam complicar esta análise, o setor de origem da produção de água e material em suspensão na bacia, aliado ao tempo de residência destes na calha fluvial e nos reservatórios, que varia ao longo do ano, parece ser fator predominante na distinção destas relações. Resultados semelhantes foram obtidos por Werneck at al. (2001) que analisou as séries temporais de diversas estações fluviométricas da Agência Nacional de Águas ao longo da cascata de barragens, como também, por Souza (2002) na análise de dados da carga de sedimentos em suspensão para a estação de Traipu no Baixo Rio São Francisco. Somente para os anos de 1999 e 2000, de comportamento hidrológico similar (Fig. 5), foram obtidas um coeficiente de regressão $\left(R^{2}\right)$ na ordem de 0,55 .

As quantidades mensais de material em suspensão, foram de $18 \pm 9 \times 10^{3} \mathrm{t} / \mathrm{mês}$ no ano de 2001 (concentração média de 4,8 mg/-!) (Fig. 11). Esta pequena variabilidade é condizente com os parâmetros de operação do sistema de barragens e com as vazões oscilando na ordem de 1.200 a $2.000 \mathrm{~m}^{3} / \mathrm{s}$. Este período é representativo da pequena entrada de água doce no sistema e da baixa produção e elevada retenção de material em suspensão, com níveis dos reservatórios e vazões defluentes gradativamente menores (Fig. 12). 
O ano de 2004 teve fluxos (Fig. 11) variando em até duas ordens de grandeza ao longo do ano, em Janeiro-Fevereiro os fluxos alcançaram valores entre $1 \mathrm{a}$ $7 \times 10^{6} \mathrm{t} / \mathrm{mês}$ (concentração média de $369 \mathrm{mg} /-$ !) de Março a Maio os valores foram na ordem de $1 \times 10^{5} \mathrm{t} /$ mês (concentração média de $25 \mathrm{mg} /-$ !); de Junho a Agosto na ordem de $0,5 \times 10^{5}$ t/mês (concentração média de $13 \mathrm{mg} /-$ ! e de Setembro a Dezembro na ordem de $0,15 \times 10^{5}$ t/mês (concentração média de 3 $\mathrm{mg} /-$ !). Desta forma, a magnitude dos fluxos de matéria em suspensão apresentou diversos estágios ao longo do ano. O primeiro estágio de janeiro-fevereiro, caracterizado pelo pico da vazão e a produção de material em suspensão geradas pela alta precipitação nos setores Sub-Médio e Baixo desde a jusante de Sobradinho até a barragem do Xingó ( i,e, com chuvas torrenciais de $254 \mathrm{~mm}$ em Janeiro na estação de Piranhas), ultrapassou a capacidade de retenção dos reservatórios com volume de menor porte $\left(S=15,8 \mathrm{Km}^{3}\right)$ e promoveu uma eficiente lavagem, produção e transporte de material à foz. O segundo e terceiro estágio mostram os reservatórios ainda com níveis altos, mas com seu volume diminuindo gradativamente, com vazões defluentes menores para o aproveitamento do potencial hidráulico e teores de material em suspensão em decréscimo devido a sedimentação. O quarto estágio representou a inflexão na curva de operação para a recuperação dos níveis dos reservatórios com águas de menores teores de material em suspensão (Fig. 12).

No inicio do mês de Janeiro de 2007 ficou evidente a recuperação dos níveis dos reservatórios com águas provenientes do Alto e Sub-Médio Rio São Francisco e com baixos teores de material em suspensão (1,4 mg/-!) devido a retenção ao longo do sistema, resultando em baixos volumes na ordem de $10 \times 10^{3} \mathrm{t} /$ mês, como mostrado na Figura 11. No segundo estágio, nos meses de Fevereiro-Abril, os volumes alcançaram valores na ordem de 2,9 $\times 10^{5} \mathrm{t} / \mathrm{mês}$ (concentração média de $23 \mathrm{mg} /-$ !). A vazão e a produção de material originado no Alto e Sub-Médio ultrapassaram a capacidade de retenção dos reservatórios de todo o sistema com volume total de água de $70,9 \mathrm{Km}^{3}$, resultando em maiores vazões mas que tiveram suas concentrações de material em suspensão eficientemente retidas (Fig. 12). O terceiro estágio, ocorreu nos meses de Maio a Julho, com cargas na ordem de $37 \times 10^{3}$ t/mês (concentração de média de $6 \mathrm{mg} /-$ !) representa os reservatórios ainda com níveis altos, mas gradativamente menores, com vazões defluentes menores para o aproveitamento do potencial hidráulico e teores de sedimentos em suspensão diminuindo devido a sedimentação nos reservatórios. O quarto estágio, de Agosto a Dezembro, foram medidos cargas na ordem de $19 \times 10^{3}$ t/mês (concentração média de 3
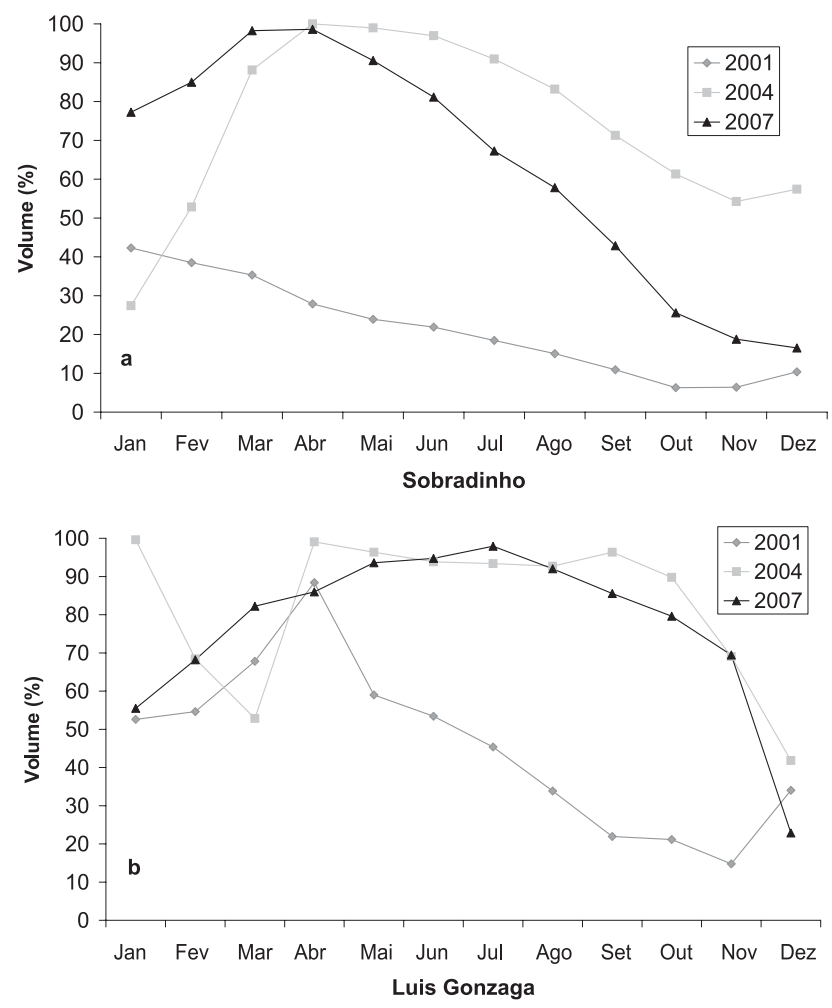

Figura 12 - Percentual de acumulação dos reservatórios de Sobradinho (a) e a montante do reservatório de Luiz GonzagaItaparica (b) nos anos de estudo. Observe o comportamento complementar na composição do nível dos reservatórios. Fonte: http:/ /www.ons.org.br, acesso em 24/06/2009.

$\mathrm{mg} /-$ !) é representativo da inflexão na curva de operação para a recuperação dos níveis dos reservatórios com águas de menores teores de material em suspensão (Fig.12).

A análise da distribuição mensal dos fluxos de material em suspensão, mostrado na Figura 11, em conjunto com as vazões dos anos de estudo (Fig. 6) indicam que os maiores aportes de 2004, ocorreram nos meses de Janeiro e Fevereiro (>90\%), em comparação ao ano de 2007 , quando $80 \%$ da carga ocorreu nos meses de Fevereiro a Abril, e sendo numa ordem de grandeza superior ao do ano inteiro de 2001.

O fator determinante do aumento no aporte de material em 2004 foi a produção de sedimentos expressa pelas maiores concentrações de material em suspensão (Fig. 9). Mesmo as maiores vazões do ano de 2007 não foram capazes de produzir aportes de sedimentos superiores aos do ano de 2004 (i.e Fev/2004 $\mathrm{Q}=4.612 \mathrm{~m}^{3} / \mathrm{s}$ e $\mathrm{Q}_{\mathrm{s}}=6,1 \times 10^{6} \mathrm{t} / \mathrm{mês} ; \mathrm{Fev} / 2007 \mathrm{Q}=$ $6889 \mathrm{~m}^{3} / \mathrm{s}$ e $\left.Q_{\mathrm{s}}=4,5 \times 10^{5} \mathrm{t} / \mathrm{mês}\right)$. Já o ano de 2001 apresentou fluxos de sedimentos em suspensão extremamente baixos onde o fluxo anual $\left(Q_{s}=2,16 \times 10^{5} \mathrm{t} /\right.$ ano) foi ligeiramente inferior ao valor do dia 12/02/2004 $\left(Q_{s}=2,17 \times 10^{5} \mathrm{t} / \mathrm{dia}\right)$. Os resultados de 2004 corroboram o potencial de produção e exportação de material quando da ocorrência de eventos extremos de precipi- 
Tabela 2- Área de drenagem, descargas de água $(Q)$, de sedimentos $\left(Q_{s}\right)$ e rendimento $(Y)$ para rios tropicais e sub-tropicais afetados pelos impactos de erosão e barragens. Entre parênteses valores mensais do aporte de água ( $\left.\mathrm{Km}^{3} / \mathrm{mês}\right)$ sedimentos em suspensão (t/ mês) e seu rendimento $\left(\mathrm{t} / \mathrm{km}^{2} \cdot \mathrm{a}\right)$.

\begin{tabular}{|c|c|c|c|c|c|}
\hline Rios & $\begin{array}{c}\text { Área } \\
\left(\times 10^{3} \mathrm{~km}^{2}\right)\end{array}$ & $\begin{array}{c}\mathbf{Q} \\
\left(\mathrm{km}^{3} \mathrm{a}^{-1}\right.\end{array}$ & $\begin{array}{c}Q_{S} \\
\left(10^{6} t . a^{-1}\right)\end{array}$ & $\begin{array}{c}\mathrm{Y} \\
\left(\mathrm{t} / \mathrm{km}^{2} \mathrm{a}^{1}\right) \\
\end{array}$ & Impactos \\
\hline São Francisco $1975^{(1)}$ & & 97 & 6,0 & 9,4 & \\
\hline $\begin{array}{l}\text { São Francisco } \\
1983-1984^{(2)}\end{array}$ & & 103 & 2,1 & 3,3 & \\
\hline $\begin{array}{l}\text { São Francisco } \\
1999-2000^{(3)}\end{array}$ & 640 & 71 & 0,4 & 0,7 & Barragens \\
\hline São Francisco $2001^{(4)}$ & & 47 & 0,2 & 0,3 & \\
\hline $\begin{array}{c}\text { São Francisco } 2004^{(4)} \\
\text { (Fevereiro) }\end{array}$ & & $\begin{array}{c}66 \\
(10)\end{array}$ & $\begin{array}{c}7,7 \\
(6,1)\end{array}$ & $\begin{array}{l}12,1 \\
(9,5)\end{array}$ & \\
\hline $\begin{array}{c}\text { São Francisco } 2007^{(4)} \\
\text { (Fevereiro) }\end{array}$ & & $\begin{array}{l}95 \\
(16)\end{array}$ & $\begin{array}{l}1,1 \\
(0,4)\end{array}$ & $\begin{array}{l}1,7 \\
(0,7)\end{array}$ & \\
\hline Paraíba do Sul(5) & 55 & 28 & 0,6 & 11 & $\begin{array}{l}\text { Erosão/ } \\
\text { Barragens }\end{array}$ \\
\hline Rio Doce ${ }^{(3,6)}$ & 90 & 20 & 9,9 & 110 & Erosão \\
\hline $\begin{array}{l}\text { Magdalena }^{(7)} \\
(\text { Colombia })\end{array}$ & 257 & 228 & 144 & 560 & Erosão \\
\hline $\begin{array}{l}\text { Chao Phraya } \\
\text { (Tailândia) }\end{array}$ & 160 & 28 & 6 & 37,5 & Barragens \\
\hline $\begin{array}{c}\text { Fly }^{(8)} \\
\text { (Nova Guiné) }\end{array}$ & 75 & & 120 & 61 & Erosão \\
\hline $\begin{array}{l}\text { Pearl }^{(9)} \\
\text { (China) }\end{array}$ & 450 & 220 & 40 & 89 & Barragens \\
\hline
\end{tabular}

(1) Milliman (1975); (2) Santos (1993); (3) Souza \& Knoppers (2003); (4) Este Estudo; (5) Carneiro (1998); (6) Souza (2002); (7) Restrepo \& Kjerfve (2000); (8) Walling, (2006); (9) Dai et. al. (2008).

tação na porção inferior da bacia do Rio São Francisco. Por outro lado, a limitação nesta produção e a diminuição da carga à costa acontecem durante períodos secos ou quando eventos de precipitação elevada ocorrem na porção superior da bacia, uma vez que as concentrações de matéria em suspensão são atenuadas pela retenção e sedimentação ao longo do sistema de barragens.

Quando comparados aos estudos pretéritos, em especial as determinações de Milliman (1975), observa-se a drástica redução das descargas específicas (i.e. rendimentos) da bacia para os sedimentos em suspensão (Y, Tabela 2), de valores em torno de $10 \mathrm{t} / \mathrm{km}^{2}$.ano do período antes da instalação da maior parte das barragens para valores atuais inferiores a $1 \mathrm{t} / \mathrm{km}^{2}$.ano após a instalação. Observa-se ainda a redução em torno de $50 \%$ dos valores de descarga de água doce $(\mathrm{Q}$, Tabela 2) no mesmo período em virtude da acumulação pelos reservatórios $\left(S=70,9 \mathrm{Km}^{3}\right)$ que representa aproximadamente a média das descargas nos três anos de estudo. Somente no evento extremo de precipitações no baixo curso no ano de 2004, em especial no mês de fevereiro, as descargas de água doce, material em suspensão e seus rendimentos alcançaram valores similares aos de 1975 (Tabela 2).
Comparativamente às bacias de drenagem de menor porte (Tabela 2), como por exemplo dos rios Magdalena (Colômbia), Pearl (China) e, Chao Praya (Tailândia) e dos rios da costa Leste Brasileira, tal como os rios Doce (ES) e Paraíba do Sul (RJ), de clima mais úmido, verifica-se que as descargas de água são proporcionalmente muito superior a do Rio São Francisco, o que ressalta o efeito de regime climático diferenciado da bacia localizada em grande parte no semi-árido do nordeste brasileiro e o aumento do potencial de retenção pelas barragens de matéria oriunda dos setores mais úmidos da bacia, além da evaporação de água dos reservatórios. Os rendimentos da produção de sedimentos da bacia ( $Y$, Tabela 2) são também de difícil comparação devido a diversidade de impactos sofridos pelas bacias de drenagem dos outros rios. Entretanto uma simplificação dos impactos erosivos e de retenção de matéria em suspensão pelas barragens, pode ser observado em sistemas úmidos e sob processo erosivo, tal como nos rios Magdalena e Fly (Pápua Guinéa), onde os rendimentos são de uma a duas ordens de grandeza superiores aos do Rio São Francisco (Tabela 2). Os sistemas sob influencia predominante do impacto de barragens têm seus rendimentos entre 11 (Rio Paraíba do Sul) e 89 t/km².ano (Rio Pearl), demonstrando o intenso impacto da retenção de mate- 
rial em suspensão pelo sistema de barragens em cascata do Rio São Francisco. Somente quando do evento extremo de precipitação de 2004 que ocorreu no baixo curso da Bacia do Rio São Francisco, os valores de rendimento da produção de sedimentos em suspensão alcançaram o limite inferior dos valores relatados para sistemas impactados por barragens.

Estes resultados evidenciam o potencial de recarga e produção de material em suspensão no setor da bacia a jusante do sistema de barragens em cascata, que pode ser estimado pelo calculo da diferença entre os aportes de material em suspensão de Fevereiro de $2004\left(Q_{s}=6,1 \times 10^{6}\right.$ t/ano), gerada pela bacia do Baixo São Francisco $\left(A_{B}=36.000 \mathrm{Km}^{2}\right.$, a jusante de Xingó), e de Fevereiro de $2007\left(Q_{s}=6,1 \times 10^{6}\right.$ t/ano) gerada por toda a bacia. O rendimento-estimado foi da ordem de $158 \mathrm{t} / \mathrm{km}^{2}$.ano e exemplifica o potencial máximo de recarga para a bacia do Baixo São Francisco, sendo bem superior a sistemas impactados por barragens e semelhantes a sistemas impactados por processos erosivos. Este elevado suprimento de material pode minimizar por algum tempo os intensos processos erosivos que ocorrem na região da foz após a operação do sistema de barragens em cascata.

\section{CONCLUSÕES}

Nos últimos 30 anos o Rio São Francisco e seu estuário sofreram grande redução na descarga de água doce e no aporte de material em suspensão. A ocorrência de eventos climáticos de secas e cheias promoveu a oportunidade da avaliação do impacto da operação do sistema de barragens em cascata. A avaliação foi realizada em condições mínimas de fluxo durante um evento de estiagem, com drástica redução dos aportes de água e material particulado, tanto quanto em condições máximas de cheias, comparando um evento de 2007 com retenção máxima de material pelas barragens produzido no Alto curso, e de máxima exportação em 2004 com a produção de material em suspensão no Baixo curso. O evento de 2004 evidenciou um potencial máximo de recarga das concentrações e fluxos de sedimentos pela bacia do Baixo Rio São Francisco com elevados rendimentos da produção de material em suspensão neste trecho, sendo bem superiores aos estimados para sistemas impactados por barragens e semelhantes ao de sistemas impactados por processos erosivos.

Os resultados demonstraram que a variabilidade espacial climática com eventos de estiagem e cheias ao longo da bacia em relação à localização da cascata de barragens no Sub-Médio semi-árido do Rio São Francisco, geram alterações significativas nas descargas de água e matéria em suspensão à zona costeira, além da capacidade de controle operacional das barragens.

\section{AGRADECIMENTOS}

A Companhia Hidrelétrica do Rio São Francisco (CHESF), Manoel Messias Santos e colegas do LABMAR pelo apoio no campo e análises de laboratório. Apoio financeiro: Projeto ANA/GEF Rio São Francisco, Sub-projeto 1.1. e Bolsa CNPq de Doutorado a P. Medeiros, Bolsas de PQ CNPq a B. Knoppers Processos No. 476833/2001-9 e 300772/2004-1, Projeto Instituto do Milênio Estuários CNPq/MCT, Proc. No. 420.050/2005-1 e CNPq INCT-TMCOcean Proc. No. $573.601 / 2008-9$.

\section{REFERÊNCIAS BIBLIOGRÁFICAS}

ANA-Agência Nacional de Águas .2005. Monitoramento do Reservatórios do Rio São Francisco - 03 de Janeiro de 2005. ANA, Brasília, 7 p.

ANA - Agência Nacional de Águas. 2008. www.ana.gov.br, 3 de Janeiro de 2008.

ANA - Agência Nacional de Águas. 2009. www.ana.gov.br, 21 de Junho de 2009.

Bernardes, L.M.C. 1951. Notas sobre o clima da bacia do Rio São Francisco. Rev. Bras. Geog. 13(3): 473489.

Carneiro, M.E.R. 1998. Origem, transporte e destino de matéria biogênica e hidrocarbonetos no estuário do Rio Paraíba do Sul. Tese de Doutorado. Departamento de Geoquímica, Universidade Federal Fluminense-UFF. 137p.

CHESF - Companhia Hidroelétrica do São Francisco, 2008. www.chesf.gov.br, 20 de março de 2008.

Dai, S. B.; Yang, S. L. \& Cai, A. M. 2008. Impacts of dams on the sediment flux of the Pearl River, southern China. Catena, 76(1):36-43.

Halim,Y. 1991. The impact of human alterations of the hydrological cycle on ocean margins. In: Mantoura, R.F.C.; Martin, J.M. \& Wollast R. (eds.) Ocean Margin Processes in Global Change. Jonh Wiley \& Sons, New York. 301-328 pp.

Hay, W.W. 1998. Detrital sediment fluxes from continents to oceans. Chem. Geol., 145(3-4):287323.

Knoppers, B.; Medeiros, P.R.P.; Souza, W.F.L.; Jennerjahn, T. 2005 The São Francisco Estuary, Brazil. In: Wangersky, P. (ed.) The Handbook of Environmental Chemistry, Vol. 5- Water Pollution: estuaries. Springer Verlag, Berlin. 51-70 pp.

Medeiros, P. R. P. 2003. Aporte fluvial, transformação e dispersão da matéria em suspensão e nutrientes 
no estuário do Rio São Francisco, após a construção da Usina Hidroelétrica do Xingó (AL/SE). Tese de Doutorado. Departamento de Geoquímica, Universidade Federal Fluminense-UFF. $184 \mathrm{p}$.

Medeiros, P.R.P.; Knoppers, B.A.; Santos Junior, R.C.; Souza, W.F.L. 2007. Aporte fluvial e dispersão da matéria particulada em suspensão na zona costeira do estuário do rio São Francisco (SE/AL). Geoch. Bras. 21(2)209-228.

Meybeck, M. 2001. River basin under anthropocene conditions. In: von Bodungen, B., and Turner, K. (eds). Science and Integrated Basin Management. Dahlem workshop series, Wiley, 307-329 pp.

Milliman, J. D. 1975. A Synthesis. In: Milliman, J.D. \& Summerhayes C.P. (eds.) Upper continental margin sedimentation of Brazil, E. Schweizerbart'sche Verlagsbuchhandlung, Suttgart. 151-175 pp.

Milliman, J.D. \& Syvitski,J.P.M. 1992. Geomorphic/ tectonic control of sediment discharge to the ocean: the importance of small mountainous rivers. J. Geol. 100(5):525-544.

Milliman, J.D. 1991. Flux and fate of fluvial sediment and water in coastal seas. In: R.F.C. Mantoura.; J.M. Martin \& R. Wollast. (Eds) Ocean Margin Processes in Global Change. Jonh Wiley \& Sons, New York. 60-90 pp.

Nimer, E. 1972. Climatologia da região Nordeste do Brasil. Rev. Bras. Geog. 34(2):3-51.

ONS - Operador Nacional do Sistema Elétrico 2001. OPHEN - Acompanhamento Diário da Operação Hidroenergética do Sistema Interligado Nacional 15/02/2001. ONS, Brasília. 6 p.

ONS - Operador Nacional do Sistema Elétrico 2004. OPHEN - Acompanhamento Diário da Operação Hidroenergética do Sistema Interligado Nacional 01/02/2004. ONS, Brasília. 10 p.

ONS - Operador Nacional do Sistema Elétrico 2007. OPHEN - Acompanhamento Diário da Operação Hidroenergética do Sistema Interligado Nacional 22/02/2007. ONS, Brasília. 10 p.

Ponte, F. C. 1969. Estudo Morfo-Estrutural da Bacia de Sergipe Alagoas. Bol. Téc. Petrobrás 12(4):439474.

Restrepo, D.J. \& Kjervfe. B. 2000. Water discharge and sediment loads from the western slopes of the Colombian Andes with focus on rio San Juan. J. Geol. 108(1): 17-33.

Santos, C. M. M. 1993. Geoquímica do carbono e nitrogênio orgânico particulado transportados durante um ano hidrológico (1984-1985) pelo rio São Fran- cisco, Brasil, e transferidos ao seu estuário. Dissertação de Mestrado. Instituto de Geociências, Universidade Federal da Bahia, $70 \mathrm{p}$.

Souza, W. F. L. 2002. A interface terra-mar leste do Brasil: tipologia, aporte fluvial, águas costeiras e plataforma continental. Tese de Doutorado. Departamento de Geoquímica, Universidade Federal Fluminense, $234 \mathrm{p}$.

Souza, W.L.F \& Knoppers, B. 2003 Fluxos de água e sedimentos a costa leste do Brasil: relações entre a tipologia e as pressões antrópicas. Geoch. Bras. 17(1):057-074.

Strickland, J. D. H. \& Parsons, T. R. 1972. A practical handbook of seawater analysis. Bulletin Fisheries Research Board of Canada, 167p.

Syvitski, J.P.M.; Peckham, S.D.; Thierry, R. \& Hilberman,M. 2003. Predicting the terrestrial flux of sediment to the global ocean: a planetary perspective. Sediment. Geol. 162(1-2):5-24.

Syvitski, J.P.M.; Vorosmarty, C.J.; Kettner, A.J. \& Green, P. 2005. Impact of human on the flux of terrestrial sediment to the global ocean. Science 308(5720): 376-380.

Tundisi, J. G.; Rocha, O.; Matsumuratundisi, T. \& Braga, B. 1998. Reservoir Management in South America. Int. J..Water Resour. D. 14(2):141-155.

Vörösmarty, C.J.; Meybeck, M.; Fekete, B. E. \& Sharma, K. (1997). The potential impact of neoCastorization on sediment transport by the global network of rivers. In: Walling, D.E. \& Probst, J.L. (eds.) Human Impact on Erosion and Sedimentation. IAHS Press, Wallinford. 261-273 pp.

Vörösmarty, C.J.; Meybeck, M.; Fekete, B.E., Sharma, K.; Green, P. \& Syvitski, J.P.M., 2003. Anthropogenic sediment retention: major global impact from registered river impoundments. Global Planet. Change 39(1-2):169-190.

Walling, D.E. 2006. Human impact on land-ocean sediment transfer by the world's rivers. Geomorphology 79(3-4):192-216.

Werneck-Lima, J.E.F.; Santos, P.M.C. dos; Chaves, A.C.M.de; Scilewski, L.R. 2001.Diagnóstico do fluxo de sedimentos em suspensão na Bacia do Rio São Francisco.ANEEL-ANA, Embrapa Cerrados, Brasilia, DF.108p. 